\title{
Estimation of Minor Loss Coefficient Associated with Fitting of Venturimeter in a Pipe System
}

\author{
C. Sivapragasam, A. Kowsiga, G. Lidwin Joan Jeraldine
}

\begin{abstract}
Quantification of minor losses associated with a pipe fitting and regular updating is necessary for ensuring the sustainability of the system. In this study, based on simple lab based experiments, the minor loss coefficient associated with a venturimeter fitted in a pipe system is estimated. It is seen that the loss coefficient varies inversely with the increase in the Reynold's number and can be depicted with a simple mathematical equation. Keywords : Loss coefficient, Minor loss, Reynold's number, Venturimeter.
\end{abstract}

\section{INTRODUCTION}

In the flow through pipe systems, major losses and minor losses need to be accounted properly in order to supply the required energy to the flow. While major losses are due to friction, minor losses are associated with change in pipe geometry (expansion, contraction, bend etc) or fitting of valve etc. Venturimeter are most widely device for measuring discharge in a pipe system. The fitting of this device in the pipe system will cause losses and these losses will be particularly significant for a small pipe system such as that used in a drip irrigation system. It is necessary to quantify these minor losses and design the energy requirement accordingly so that sustainability of the system can be ensured. Generally, the minor losses are expressed as a function of velocity head. To estimate the minor loss due to fitting of venturimeter, the loss coefficient has to be estimated. There is no explicit reported work in the said objective, except a few related works. For instance, Farsirotou et al (2014) conducted experimental studies to estimate the minor losses associated with a Reynold's number indicated that for Reynold's number between 2000 to 5000, the non-dimensional number head loss (which is essentially the loss coefficient) decreased after which it remains constant within the statistical error. The current work differs from the previously reported work in the sense that a procedure for minor loss estimation associated with the venturimeter as a whole based on the experimental set-up available in fluid mechanics laboratory is proposed.

Further, the experiment has been conducted for Reyonld's number upto 55000

Revised Manuscript Received on December 13, 2019.

* Correspondence Author

Dr.C.Sivapragasam*,Center of water technology, department of Civil Engineering, Kalasalingam Academy of Research and Education, Krishnan kovil, Tamilnadu, India..Email: sivapragasam@klu.ac.in

A.Kowsiga, department of Civil Engineering, Kalasalingam Academy of Research and Education, krishnankovil, India. Email: pushikowsi@gmail.com

G.Lidwin Joan Jeraldine, department of Civil Engineering, Kalasalingam Academy of Research and Education, krishnankovil, India. Email: lidwinprince98@gmail.com.

\section{METHODOLOGY}

In the experimental set-up, water enters the horizontal venturimeter fitted in a circular pipe of $40 \mathrm{~cm}$ diameter. The venture consists of a converging section, a throat (of diameter $20 \mathrm{~cm}$ ) and a gradually diverging section. A differential water manometer is fitted between the inlet pipe and the throat of the venturimeter as shown in Figure 1

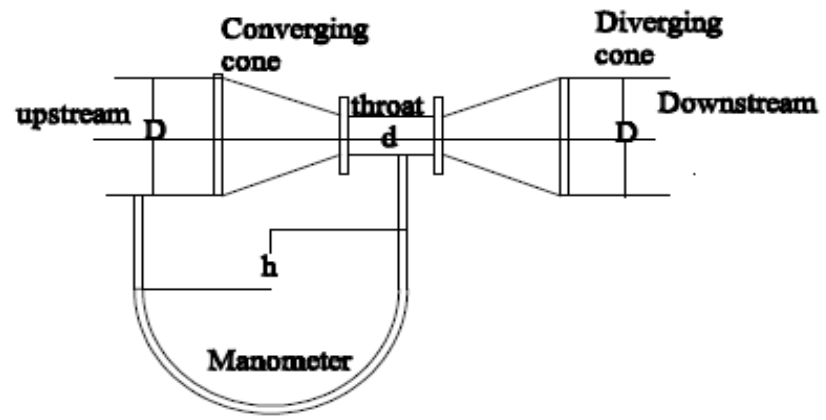

Fig. 1. Venturimeter

The overall methodology adopted is discussed as below: From the manometer fitted between the convergent section of the venturimeter and the throat, the pressure drop is estimated. Bernoulli's equation is used to measure the head loss in this section.

$$
\frac{P_{1}}{\gamma}+\frac{V_{1}^{2}}{2 g}+Z_{1}=\frac{P_{2}}{\gamma}+\frac{V_{2}^{2}}{2 g}+Z_{2} h_{L}
$$

where $h_{L}$ is the head loss between the section 1 and 2 . The other three terms are pressure head, velocity head and datum head at sections 1 and 2 respectively. The head loss includes both the friction loss (major loss) as well as the minor loss associated with the fitting of the venturimeter. Since, the length of venturimeter is very small, and for the discharge range considered, it is safe to neglect the major loss without loss of accuracy. Hence the term $h_{L}$ represents only the minor loss. $p_{1}$ and $p_{2}$ represents the pressures at the sections 1 and 2 respectively. The velocity is estimated by measuring the discharge in the collecting tank of area ' $A$ ' for ' $x$ ' $\mathrm{cm}$ rise in the water level at time $t$. The velocity of flow, $\mathrm{V}$, through the pipe is calculated by dividing the actual discharge Qa in the pipe with the area 'A' of the pipe.

$\mathrm{Q}_{\mathrm{a}}$ is given by

$Q_{a}=\frac{A x}{t}$

The head loss in the divergent section is assumed to be same as that obtained in the convergent section for a given discharge.

The total head loss $\left(\mathrm{h}_{\mathrm{L}}\right)$ is obtained as the sum of head loss in convergent and divergent sections. 


\section{Estimation of Minor Loss Coefficient Associated with Fitting of Venturimeter in a Pipe System}

In order to reduce the effect of experimental errors, the following steps are taken. The experiments are done in the possible wide range of discharges as per the limit of the apparatus. As many as 28 readings are taken. Since $C_{d}$ is expected to be more when the discharge is high and vice versa, it is expected that loss coefficient will also vary with discharge. Further, one can obtain same $\mathrm{C}_{\mathrm{d}}$ value for different combinations of head difference and discharge due to experimental errors. It is hence recommended to find the values of loss coefficient for average head loss and discharge combinations corresponding to $\mathrm{C}_{\mathrm{d}}$ values of $0.97,0.98$ and 0.99 .

To estimate $C_{d}$, the following equation is used

$C_{d}=\frac{Q_{a}}{Q_{t}}$

where $\mathrm{Q}_{\mathrm{t}}$ is the theoretical discharge estimated as

$Q_{t}=\frac{A_{\perp A_{2}}}{\sqrt{A_{2}^{2}-A_{1}^{2}}} \sqrt{2 g h}$

where $A_{1}$ and $A_{2}$ are the areas of pipe and throat section of venturimeter respectively. ' $h$ ' is the venture head and is calculated as the difference in the manometer reading for a water manometer.

Loss coefficient $\left(\mathrm{K}_{\mathrm{ventur}}\right)$ is then calculated from the following equation.

$$
K_{\text {venturi }}=\frac{h_{L}}{\left(\frac{V^{2}}{2 g}\right)}
$$

A graph is plotted between the non-dimensional number $\mathrm{K}_{\text {venturi }}$ and the Reynold's number and equation is fitted to explain the variation. For more details on venturimeter, the readers are referred to standard text books in Fluid Mechanics [F.M. White (2011), J.M. Cimbala and Y.A. Cengel (2014)]

\section{RESULT AND DISCUSSION}

A total of 28 readings are taken involving measurement of mass flow rate and the differential pressure. The values of $\mathrm{Q}_{\mathrm{a}}$, $\mathrm{Q}_{\mathrm{t}}$ and $\mathrm{C}_{\mathrm{d}}$ (coefficient of discharge) are also calculated. As expected, it is seen that same $\mathrm{Cd}$ values are obtained for different combinations of discharge and pressure head differences. The readings corresponding to Cd values of 0.97 , 0.98 and 0.99 are collected together and plotted as graphs between the discharge and the pressure head difference. A best fit curve is fitted through each of these graphs from which values are read for a uniform interval of Qa. Table I shows the reading obtained, and a typical best fit curve corresponding to $C_{d}$ of $0.99, C_{d}$ of 0.98 and $C_{d}$ of 0.97 is given in Figure 3,4 and 5

TABLE- I: DISCHARGE VARIATION WITH RESPECT TO PIEZOMETRIC HEAD

\begin{tabular}{|l|l|l|l|l|}
\hline \multirow{2}{*}{$\begin{array}{c}\text { S.N } \\
\mathbf{0}\end{array}$} & \multicolumn{4}{|c|}{ Loss coefficient } \\
\cline { 2 - 5 } & $\boldsymbol{h}_{\boldsymbol{1}}(\boldsymbol{m})$ & $\boldsymbol{h}_{2}(\boldsymbol{m})$ & $\boldsymbol{t}(\boldsymbol{s})$ & $\boldsymbol{Q a}\left(\boldsymbol{m}^{3} / \boldsymbol{s}\right)$ \\
\hline 1 & 0.515 & 0.325 & 20 & $6.25 \mathrm{E}-04$ \\
\hline 2 & 0.412 & 0.113 & 41 & $3.05 \mathrm{E}-04$ \\
\hline 3 & 0.468 & 0.355 & 26 & $4.81 \mathrm{E}-04$ \\
\hline
\end{tabular}

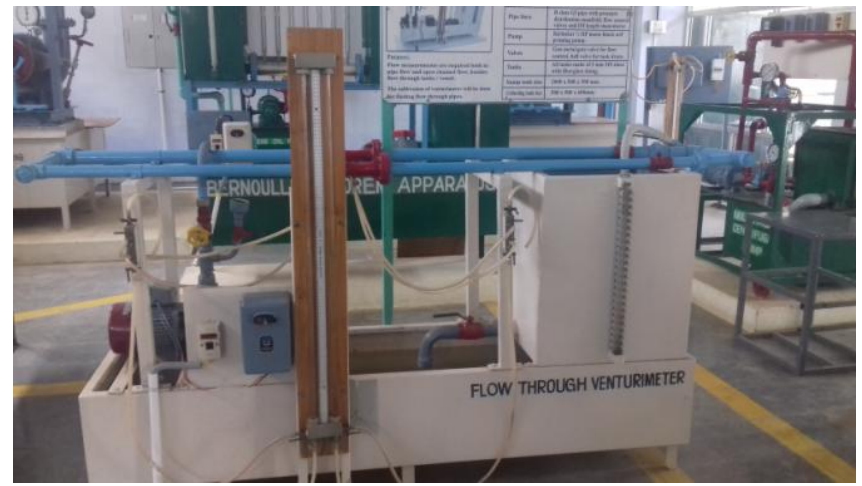

Fig. 2.Experimental setup of venturimeter 
Cd 0.99 values

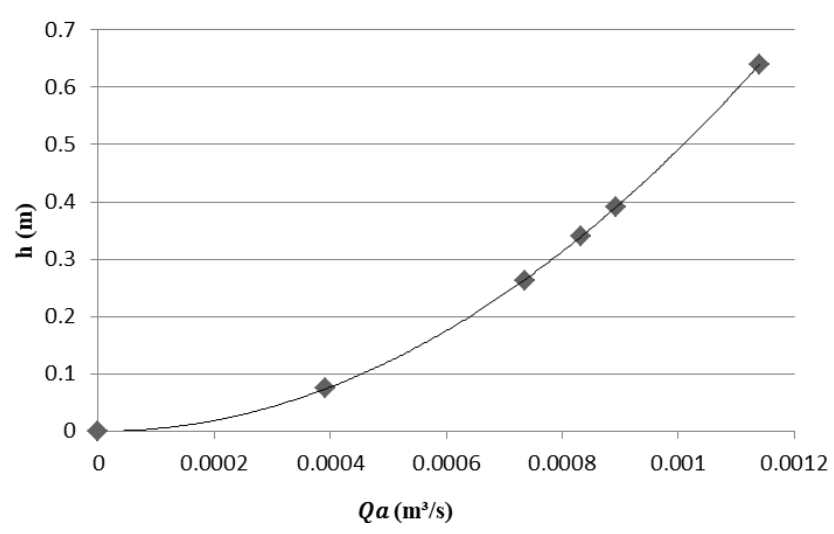

Fig. 3.Consolidated graphical representation for Cd 0.99

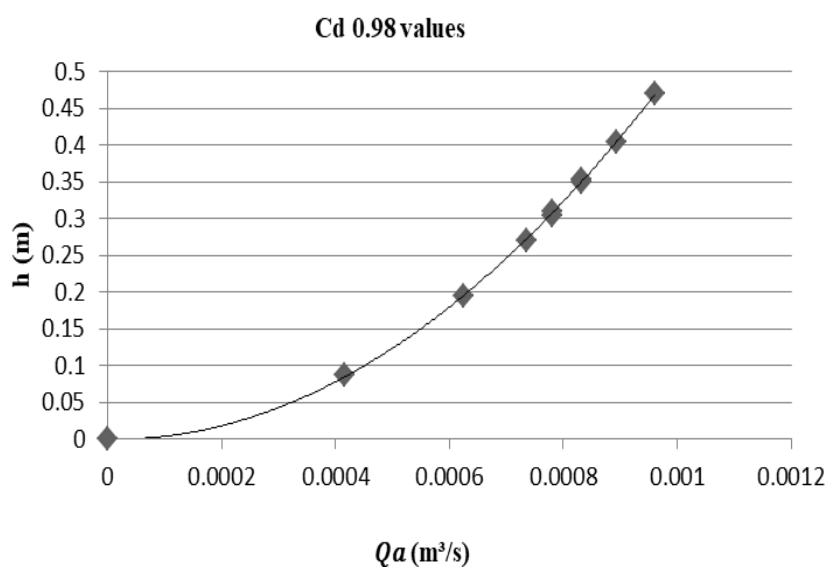

Fig. 4.Consolidated graphical representation for $\mathrm{Cd} 0.98$

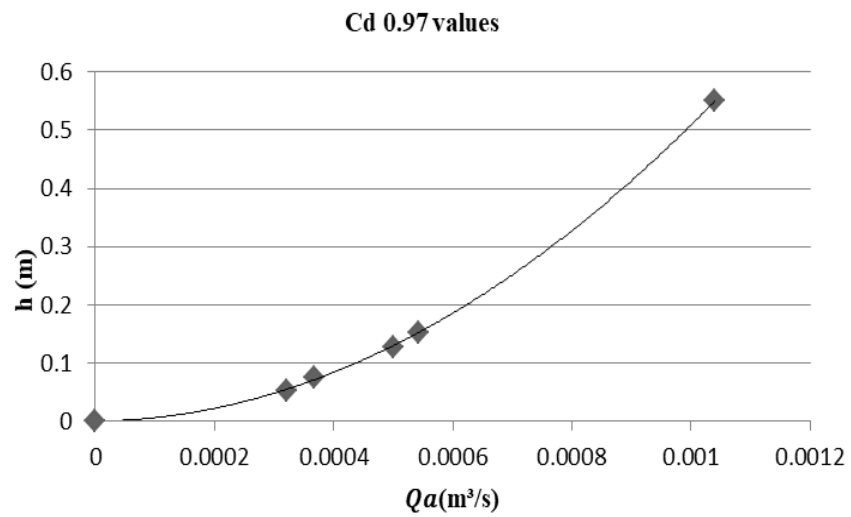

Fig. 5. Consolidated graphical representation for $\mathrm{Cd} \mathbf{0 . 9 7}$

TABLE- II: VENTURI LOSS COEFFICIENT FOR DIFFERENT FLOW CONDITIONS

\begin{tabular}{|c|c|c|}
\hline \multirow{2}{*}{ Data } & \multicolumn{2}{|c|}{ Minor Loss } \\
\hline & $R e$ & Kventuri \\
\hline 1 & 16821.31 & 0.792399 \\
\hline 2 & 19874.42 & 1.261548 \\
\hline 3 & 23457.85 & 1.016904 \\
\hline 4 & 28078.18 & 0.758335 \\
\hline 5 & 36514 & 0.710016 \\
\hline 6 & 45756.23 & 0.358255 \\
\hline 7 & 54329.12 & 1.192663 \\
\hline
\end{tabular}

Table II shows the loss coefficient values corresponding to the associated Reynold's number presented in the order of increasing Reynold's number. Considering the statistical error associated with the experiment, it is desired to plot the variation of average Reynold's number in the range 15000 18000,18000 - 20000, 20000 - 24000, 24000 - 30000, $30000-40000,40000-50000$ and $50000-60000$ and with the average loss coefficient values.

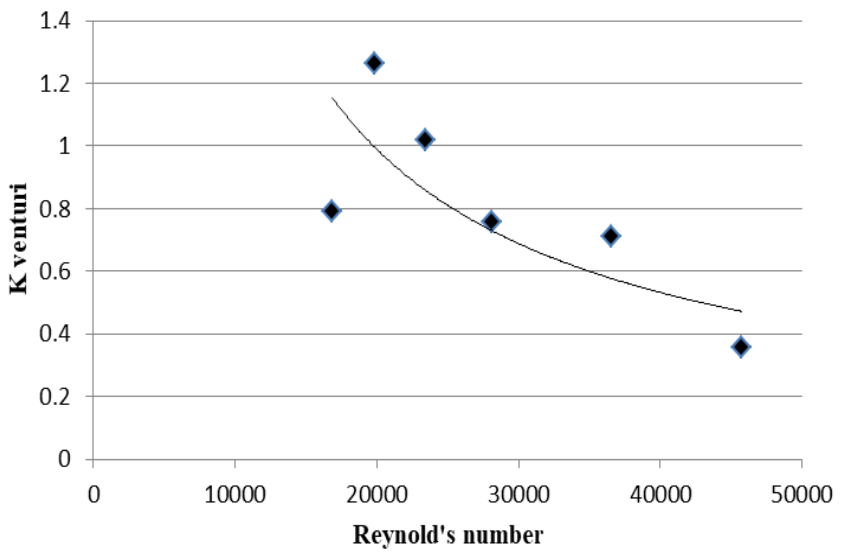

Fig. 6.Variation of Venturi loss coefficient and Re.

Figure 6 shows the plot. At Reynold's number less than 19000, there is an increase in loss coefficient and as Reynold's number increases beyond 20000, the loss coefficient is found to decrease. A best fit line is fitted to obtain the approximate equation as shown below

$K_{\text {venturi }}=6943 R_{e}^{-0.89}$

Where Re is the Reynold's number

It can be seen that the loss coefficient for the venturimeter is not a constant. It varies with discharge and as the discharge increases (i.e. Reynold's number increases), the loss coefficient decreases. It is to be noted that the assumption of same head loss in the divergent section of the pipe will introduce some error. The equation 6 valid for Reynolds number range from 15,000 to 60,000

\section{CONCLUSION}

The fitting of the venturimeter in the pipe system will incur some minor losses. The venturi loss coefficient corresponding to this minor loss is estimated and is found to decrease with the increase in the discharge or Reynold's number. It is recommended that any pipe system fitted with venturimeter should be regularly calibrated for loss coefficient so that the sustainability of the system can be better ensured. The method suggested in this paper is an approximately method involving assumption on pressure variation from throat of venturimeter to the downstream pipe. More elaborate studies can be done the actual and accurate measurement. 


\section{REFERENCES}

1. Farsirotou, E., Kasiteropoulou, D., \& Stamatopoulou, D. (2014). Experimental investigation of fluid flow in horizontal pipes system of various cross-section geometries. In EPJ Web of Conferences (Vol. 67, p. 02026). EDP Sciences.W.-K. Chen, Linear Networks and Systems (Book style). Belmont, CA: Wadsworth, 1993, pp. 123-135.

2. Frank M White, Fluid mechanics, 7th ed., The McGraw-Hill, 2011.

3. John M. Cimbala and Yunus A. Cengel, Fluid Mechanics: Fundamentals and Applications, 3rd ed. The McGraw-Hill: 2014

\section{AUTHORS PROFILE}

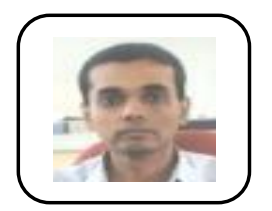

Dr. C.Sivapragasam has completed his graduation and post-graduation from IIT-Roorkee and IIT-Delhi respectively. He completed his PhD from NUS, Singapore. He has 2 years of industry experience and more than 17 years of teaching experience. He has completed 3 sponsored research projects from various funding agencies and published more than 70 papers in peer reviewed journals and conferences.

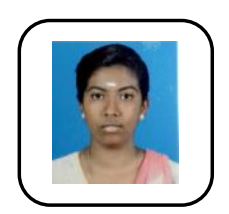

A.Kowsiga is currently pursuing her final yea undergraduation in the Department of Civil Engineering, Kalasalingam Academy of Research And Education. She has keen interest in the field of environment and water resources engineering.

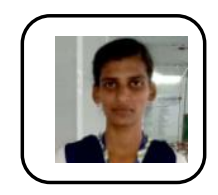

G.Lidwin Joan Jeraldine is currently pursuing her final year undergraduation in the Department of Civil Engineering, Kalasalingam Academy of Research And Education. She has keen interest in the field of environment and water resources engineering. 